1,2 Department of Biomedical Sciences ${ }^{1}$ and Department of Microbiology and Immunology2, University of South Alabama, Mobile, AL 36688, USA

3 Biotechnology Laboratory and Departments of Biochemistry and Microbiology, University of British Columbia, Vancouver, British Columbia, Canada V6T 1 Z3

4 Department of Biochemistry, Imperial College of Science, Technology and Medicine, London SW7 2AY, UK

\section{The rpoS-dependent starvation-stress response locus stiA encodes a nitrate reductase (narZYWV) required for carbon-starvation- inducible thermotolerance and acid tolerance in Salmonella typhimurium}

\author{
Michael P. Spector, ${ }^{1}$ Francisco Garcia del Portillo, ${ }^{3} \dagger$ \\ Shawn M. D. Bearson, ${ }^{2} \ddagger$ Atif Mahmud, ${ }^{1}$ Maureen Magut, ${ }^{1}$ \\ B. Brett Finlay, ${ }^{3}$ Gordon Dougan, ${ }^{4}$ John W. Foster ${ }^{2}$ \\ and Mark J. Pallen $\mathbb{4}^{\mathbb{S}}$ \\ Author for correspondence: Michael P. Spector. Tel: +1 334380 2710. Fax: +1 3343802711. \\ e-mail:mspector@usamail.usouthal.edu
}

\begin{abstract}
The starvation-stress response (SSR) of Salmonella typhimurium includes gene products necessary for starvation avoidance, starvation survival and virulence for this bacterium. Numerous genetic loci induced during carbon-source starvation and required for the long-term-starvation survival of this bacterium have been identified. The SSR not only protects the cell against the adverse effects of long-term starvation but also provides cross-resistance to other environmental stresses, e.g. thermal challenge $\left(55^{\circ} \mathrm{C}\right)$ or acid-pH challenge (pH 2-8). One carbon-starvation-inducible lac fusion, designated stiA was previously reported to be a $\sigma^{\mathrm{S}}$-dependent SSR locus that is phosphatestarvation, nitrogen-starvation and $\mathrm{H}_{2} \mathrm{O}_{2}$ inducible, positively regulated by (p)ppGpp in a relA-dependent manner, and negatively regulated by CAMP : CAMP receptor protein complex and OxyR. We have discovered through sequence analysis and subsequent biochemical analysis that the stiA::lac fusion, and a similarly regulated lac fusion designated sti-99, lie at separate sites within the first gene (narZ) of an operon encoding a cryptic nitrate reductase (narZYWV) of unknown physiological function. In this study, it was demonstrated that narZ was negatively regulated by the global regulator Fnr during anaerobiosis. Interestingly, narZ(YWV) was required for carbonstarvation-inducible thermotolerance and acid tolerance. In addition, narZ expression was induced $\sim 20$-fold intracellularly in Madin-Darby canine kidney epithelial cells and $\sim 16$-fold in intracellular salts medium, which is believed to mimic the intracellular milieu. Also, a narZ1 knock-out mutation increased the $\mathrm{LD}_{50} \sim 10$-fold for S. typhimurium SL1344 delivered orally in the mouse virulence model. Thus, the previously believed cryptic and constitutive narZYWV operon is in fact highly regulated by a complex network of environmental-stress signals and global regulatory functions, indicating a central role in the physiology of starved and stressed cells.
\end{abstract}

Keywords: nitrate reductases, stiA, thermotolerance, acid tolerance, starvation-stress response

\footnotetext{
Present Address: Centro de Biologia Molecular 'Severo Ochoa', Universidad Autónoma de Madrid, 28049 Madrid, Spain.

†Present Address: Department of Microbiology and Molecular Genetics, University of California at Los Angeles, Los Angeles, CA 90095, USA.

\$Present Address: Microbial Pathogenicity Research Group, Department of Medical Microbiology, St. Bartholomew's and the Royal London School of Medicine and Dentistry, London EC1A 7BE, UK.

Abbreviations: CRP, CAMP receptor protein; ISM, intracellular salts medium; LB, Luria-Bertani; MDCK, Madin-Darby canine kidney; MS loPCN, MOPSbuffered salts medium limiting for glucose; MS hiPCN, MOPS-buffered salts medium non-limiting for glucose, phosphate and nitrogen; SP-PCR, single-primer polymerase chain reaction; SSR, starvation-stress response; NR, nitrate reductase.
} 


\section{INTRODUCTION}

The microenvironments that bacteria, such as the serovars of Salmonella enterica (e.g. S. enterica serovar Typhimurium, referred to here as S. typhimurium), encounter as they cycle from their natural animal or human hosts to various aquatic and terrestrial microcosms are frequently limiting in the bioavailability of nutrients and fraught with a variety of potentially lethal stresses (Koch, 1971; Harder \& Dijkhuizen, 1983; Roszak \& Colwell, 1987; Morita, 1988; Moriarty \& Bell, 1993; Foster \& Spector, 1995). Therefore, Salmonella must be able to sense, respond to and adapt to changing environments in order to survive extensive periods of nutrient starvation and/or other stresses while retaining their pathogenic capabilities (Brown \& Williams, 1985; Babior, 1992; Foster \& Spector, 1995). Thus, the response and survival strategies of these bacteria may have important consequences for the epidemiology and virulence of salmonelloses.

The common stress of starvation for essential nutrients, especially an energy-yielding carbon (C) source, leads to a myriad of changes in cellular metabolism and patterns of gene expression in the bacterium referred to as the starvation-stress response (SSR) (Foster \& Spector, 1986; Spector et al., 1986, 1988; Spector, 1990, 1998; Spector \& Foster, 1993). The function of the SSR is to allow the bacteria to survive periods of long-term starvation (Spector \& Cubitt, 1992; Spector \& Foster, 1993; O'Neal et al., 1994). In addition, induction of the SSR, particularly by C starvation, increases bacterial resistance to a number of other environmental stresses, such as the presence of $\mathrm{H}_{2} \mathrm{O}_{2}$ or antimicrobial peptides, and extremes in temperature, $\mathrm{pH}$ and osmolarity (Jenkins et al., 1988; Matin, 1991; Lange \& Hengge-Aronis, 1991; McCann et al., 1991; Fang et al., 1992; Seymour et al., 1996; McLeod \& Spector, 1996; M. P. Spector, unpublished).

Over the past several years, we have created a library of starvation-inducible loci using MudJ-directed operonfusion techniques (Castilho et al., 1984; Spector et al., 1988, 1999; reviewed by Spector, 1998). Two of the fusions (designated stiA and sti-99) identified from this library are induced during $\mathrm{C}$, phosphate $(\mathrm{P})$ and nitrogen (N) starvation. The loci defined by the stiA and sti-99 insertion mutations are dependent upon the starvation-/ stress-specific sigma factor encoded by the rpoS gene, $\sigma^{\mathrm{S}}$ or $\sigma^{38}$ (Mulvey \& Loewen, 1989; Tanaka et al., 1993; for reviews see Loewen \& Hengge-Aronis, 1994; Hengge-Aronis, 1993, 1996; Spector, 1998). Both insertion mutations reduced the long-term-starvation survival of S. typhimurium some 50- to 100-fold (Spector \& Cubitt, 1992; O’Neal et al., 1994; M. P. Spector, unpublished) and thus represent core SSR loci. In addition, both the stiA and sti-99::lac fusions are negatively regulated by the cAMP:cAMP receptor protein (CRP) complex and positively regulated by guanosine tetraphosphate (ppGpp) in a relA-dependent manner (Spector \& Cubitt, 1992; M. P. Spector, unpublished; for review see Cashel et al., 1996).
The stiA and sti-99 products are also needed to generate $\mathrm{H}_{2} \mathrm{O}_{2}$-inducible $\mathrm{H}_{2} \mathrm{O}_{2}$ resistance (Seymour et al., 1996; M. P. Spector, unpublished). The $\mathrm{H}_{2} \mathrm{O}_{2}$-inducible $\mathrm{H}_{2} \mathrm{O}_{2}$ resistance pathway is controlled by the products of both the oxyR and rpoS genes (Seymour et al., 1996; Storz et al., 1990; for review see Storz \& Altuvia, 1994). Interestingly, the stiA locus is repressed by the OxyR protein (reduced form) in the absence of $\mathrm{H}_{2} \mathrm{O}_{2}$ in exponential-phase cells. In the presence of $\mathrm{H}_{2} \mathrm{O}_{2}$, stiA becomes derepressed, presumably as a result of oxidation of the OxyR protein, so that OxyR (oxidized form) no longer functions as a repressor of stiA in exponential-phase cells. However, the $\mathrm{H}_{2} \mathrm{O}_{2}$-induced levels of stiA are only about one-third of the level observed in C-starved cells, probably resulting from repression mediated by the cAMP:CRP complex in exponential-phase cells (Spector \& Cubitt, 1992; Seymour et al., 1996). Thus, the stiA and sti-99: : lac fusions are positively regulated by $\sigma^{\mathrm{s}}$ and (p)ppGpp, and negatively regulated by cAMP:CRP and OxyR.

We report here that the MudJ (lac) fusions defining the stiA and sti-99 loci are located at different sites in the same gene. Furthermore, this gene is orthologous to Escherichia coli narZ, the first gene of the narZYWV operon which encodes a nitrate reductase (NR) activity previously thought to be cryptic and constitutive (NRZ) (Barrett \& Riggs, 1982; Blasco et al., 1990; Bonnefoy \& DeMoss, 1994). As previously reported for both $E$. coli and Salmonella, NR-Z, unlike the narGHJI-encoded NR-A, is not synthesized during anaerobiosis nor is it responsive to exogenously added nitrate during anaerobiosis or aerobiosis (Barrett \& Riggs, 1982; Bonnefoy \& DeMoss, 1994; reviewed by Gennis \& Stewart, 1996). In fact, narZYWV was repressed during anaerobic growth conditions by the $f n r$ gene product, Fnr. We also report that NR-Z was required for C-starvation-inducible thermotolerance and acid tolerance and was significantly induced within vacuoles of MDCK epithelial cells (Garcia del Portillo et al., 1992) in culture as well as in intracellular salts medium (ISM) (Wilson et al., 1997). Furthermore, a knock-out mutation of narZ increased the $\mathrm{LD}_{50}$ of wild-type cells some 10 -fold following oral inoculation in the mouse virulence model for Salmonella.

\section{METHODS}

Bacterial strains, phage and transductions. The strains used in this study, unless otherwise indicated, were all derivatives of the virulent Salmonella enterica serovar Typhimurium (referred to here as Salmonella typhimurium) strain SL1344 and are listed in Table 1. Transductions were performed using a high transducing derivative of $S$. typhimurium bacteriophage P22, P22 HT 105/1 int (HT phage) (Chan et al., 1972). In all cases, transductants were determined to be non-lysogens for phage P22 by growth on Green indicator plates (Davis et al., 1980) and sensitive to the H5 derivative of P22 (Maloy, 1990).

Culture media, supplements and antibiotics used. The minimal medium used in this study was a modified MOPSbuffered salts (MS)-based medium (Neidhardt et al., 1974; described in detail by Spector et al., 1988; Spector \& Cubitt, 1992). MS medium nonlimiting in glucose, phosphate and 
Table 1. Salmonella enterica sv. Typhimurium strains used in this study

\begin{tabular}{|c|c|c|}
\hline Strain & Genotype (pertinent phenotype)* & Source/reference \\
\hline SL1344 & hisG46 (virulent Salmonella typhimurium) & Hoiseth \& Stocker (1981) \\
\hline ST63 & SL1344 narZ2 (sti-99):: MudJ (lac Kan $\left.{ }^{\mathrm{R}}\right)$ & This study \\
\hline ST66 & SL1344 narZ1 (stiA1) : : MudJ $\left(\operatorname{lac} \operatorname{Kan}^{\mathrm{R}}\right)$ & Spector et al. (1988); O’Neal et al. (1994) \\
\hline SMS438 & SL1344 rpoS: : $\Omega-\mathrm{Amp}^{\mathrm{R}}$ & Fang et al. (1992); O’Neal et al. (1994) \\
\hline SMS575 & ST66 fnr:: Tn10 $\left(\right.$ Tet $\left.^{\mathrm{R}}\right)$ & This study; J. Foster $†$ \\
\hline SMS643 & SL1344 narGHIJ1715:: MudJ (lac $\left.\operatorname{Kan}^{\mathrm{R}}\right)$ & This study; V. Stewart $\ddagger$ \\
\hline
\end{tabular}

$* \operatorname{Kan}^{\mathrm{R}}$, kanamycin resistance; $\mathrm{Amp}^{\mathrm{R}}$, ampicillin resistance; $\mathrm{Tet}^{\mathrm{R}}$, tetracycline resistance.

† John Foster, University of South Alabama, USA.

$\ddagger$ Valley Stewart, University of California, Davis, USA.

nitrogen (MS hiPCN) was used to generate exponential-phase cells while MS medium limiting in glucose $(0.03 \% \mathrm{w} / \mathrm{v} ; \mathrm{MS}$ loC) was used to generate C-starved cells. The rich medium used was Luria-Bertani (LB) agar and broth (Davis et al., 1980; Difco). ISM was obtained from Dr Paul Gulig, University of Florida College of Medicine (Wilson et al., 1997).

Histidine was added, as needed, to a final concentration of $0.2 \mathrm{mM}$. Kanamycin (Kan) and chloramphenicol (Cam) were each used, as needed, at a final concentration of $100 \mu \mathrm{g} \mathrm{ml} l^{-1}$. Tetracycline (Tet) was used at the final concentration of $20 \mu \mathrm{g}$ $\mathrm{ml}^{-1}$ in rich medium and $10 \mu \mathrm{g} \mathrm{ml} \mathrm{m}^{-1}$ in minimal medium. Ampicillin (Amp) was used at a final concentration of $30 \mu \mathrm{g}$ $\mathrm{ml}^{-1}$.

Analysis and DNA sequencing of $S$. typhimurium DNA flanking the stiA and sti-99 MudJ insertion sites. DNA adjacent to the stiA::MudJ insertion site was cloned by digesting chromosomal DNA isolated from strain ST66 with SalI, using protocols supplied by the manufacturer (Promega). SalI was chosen because there is a single site within MudJ, about $2.5 \mathrm{~kb}$ from the left end of MudJ and just upstream from the $\mathrm{Kan}^{\mathrm{R}}$ gene, so that SalI restriction fragments of $2.5 \mathrm{~kb}$ or greater would contain the $\mathrm{Kan}^{\mathrm{R}}$ gene and remaining MudJ DNA plus any chromosomal DNA adjacent to the insertion site. SalI fragments were separated in a TBE $0.7 \%$ agarose gel. Restriction fragments between 2.5 and $8 \mathrm{~kb}$ were purified by cutting out the corresponding region from the gel, freezethawing and mashing the gel slice with a sterile pestle, adding $100 \mu \mathrm{l}$ TE (10 mM Tris, $1 \mathrm{mM}$ EDTA) buffer and subjecting the mixture to filtration through a ULTRAFREE-MC filter unit (Millipore). The filtrate was collected, ethanol precipitated and resuspended in $50 \mu \mathrm{l}$ sterile distilled water (target DNA). Target DNA was then mixed with SalI-digested pACYC184, ligated with T4 ligase and electrotransformed into electrocompetent recipient cells, selecting for $\mathrm{Kan}^{\mathrm{R}}$ (target DNA) and $\mathrm{Cam}^{\mathrm{R}}$ (vector DNA). $\mathrm{Kan}^{\mathrm{R}} \mathrm{Cam}^{\mathrm{R}}$ transformants were picked, and their plasmids were isolated using Wizard Mini-prep columns (Promega), digested with SalI and analysed by TBE $0.7 \%$ agarose gel electrophoresis. The plasmid carrying the desired fragment, pSS1, was then used for sequencing of the target DNA via dideoxynucleotide sequencing using protocols supplied by the manufacturer (Promega).

The insertion sites for both the stiA::lac and sti-99::lac were also analysed using an adaptation of the single-primer PCR (SP-PCR) method of Parks et al. (1991), which is described in detail by Spector et al. (1999). SP-PCR was performed on cell lysates from ST63 and ST66 and the wild-type parent SL1344.
Briefly, this method relies on the use of a single PCR primer designed to prime DNA synthesis out of the left end of MudJ (MudL; GenBank accession no. M10190) into adjacent chromosomal DNA. However, exponential amplification of the MudJ/chromosome junction site only occurs if the MudL primer also binds to a stretch of partially complementary sequence in the region of unknown sequence on the opposite strand. Fortunately, this occurs at a sufficiently high frequency so as to be useful if one or more of the PCR cycles includes a low annealing temperature. If successful, this primer should yield a product possessing a $34 \mathrm{bp}$ sequence between the primer-binding site and the end of the $\mathrm{MudL}$ sequence at one of its ends. Products not containing this $34 \mathrm{bp}$ region were considered artifacts of the procedure and not studied further.

PCR products were first analysed and then ligated to the pGEM-T plasmid prior to being transformed into hypercompetent HB101 cells (supplied with the vector) according to the manufacturer's instructions (Promega). White colonies on LB Amp IPTG X-Gal plates (which contain vector and insert) were subcultured, and their plasmids were isolated and analysed via PCR using forward and reverse vector-specific primers (Promega). Five microlitre aliquots of the completed reactions were run on a TBE $1 \%$ agarose gel to determine the presence and size of any insert. Amplified inserts were then PEG precipitated (Rosenthal et al., 1993) and sequenced by Taq cycle sequencing using forward and/or reverse primers with subsequent analysis on an ABI 377 automated sequencer (Applied Biosystems).

Growth and starvation conditions. The desired strains were grown overnight in MS hiPCN, with antibiotic as needed, at $37^{\circ} \mathrm{C}$ with shaking. Overnight cultures were then diluted $1: 100$ into $4 \mathrm{ml}$ fresh MS hiPCN with shaking in a $20 \mathrm{~mm}$ test tube (to generate exponential-phase aerobically grown cells) or static (overlaid with sterile mineral oil) in a $13 \mathrm{~mm}$ test tube (to generate exponential-phase anaerobically grown cells) with or without $50 \mathrm{mM}$ potassium nitrate, or $4 \mathrm{ml}$ fresh MS loC with shaking in a $20 \mathrm{~mm}$ test tube, and incubated at $37^{\circ} \mathrm{C}$. Growth was monitored by measuring $A_{600}$. Cells were grown in MS hiPCN to $A_{600}$ of $0.3-0 \cdot 4$ (exponential phase) with or without nitrate and assayed for nitrate reductase activity and/or $\beta$-galactosidase activity. Three-hour C-starved cells were obtained by growing the cells in MS loC broth until growth stopped as a result of exhaustion of glucose and continuing to starve the cells for a total of $3 \mathrm{~h}$, at which point cells were assayed for nitrate reductase and/or $\beta$-galactosidase activity.

Enzyme assays. NR activity was measured at desired time intervals. Depending on whether high or low activity was 
expected, $0.5 \mathrm{ml}$ or $1.5 \mathrm{ml}$, respectively, of culture was removed, centrifuged and the supernatant discarded. The cells were then washed twice in $1 \mathrm{ml}$ MS buffer (to remove any $\mathrm{NO}_{2}$ present). The washed cells were resuspended in $1 \mathrm{ml}$ MS buffer plus $5 \mathrm{mM} \mathrm{KNO}$ and incubated for $30 \mathrm{~min}$ at $37^{\circ} \mathrm{C}$. The suspension was then centrifuged and $0.5 \mathrm{ml}$ supernatant was mixed with $0.5 \mathrm{ml}$ Greiss reagent (Sigma) and allowed to develop at room temperature for $15 \mathrm{~min}$. The $A_{540}$ was then measured and recorded. Nanomoles of $\mathrm{NO}_{2}$ produced were determined from a standard curve for known $\mathrm{NO}_{2}$ concentrations. NR activity was measured as nmol $\mathrm{NO}_{2}$ formed $\div$ $\left(A_{600} \times 15 \mathrm{~min} \times 0.5\right.$ or $1.5 \mathrm{ml}$ cells); where $A_{600}$ is $A_{600}$ of culture at the point of assay. An NR unit equals $1 \mathrm{nmol} \mathrm{NO}_{2}$ formed $\min ^{-1}\left(A_{600} \times \text { vol. cells }\right)^{-1} . \beta$-Galactosidase activity was measured by the method of Miller and is expressed in Miller units (Miller, 1972; 1992).

Thermotolerance and acid-tolerance protocols. To test for Cstarvation-inducible resistance mechanisms, cells were grown as described above. At appropriate time intervals, aliquots of aerobically grown exponential-phase, $5 \mathrm{~h} \mathrm{C}$-starved and $24 \mathrm{~h}$ C-starved cells were diluted 1:100 in MS buffer at $55^{\circ} \mathrm{C}$ (for thermotolerance) or MS buffer at $\mathrm{pH} 2 \cdot 8$ (for acid tolerance). To determine survival during thermal challenge, aliquots were removed every 4 min from time zero up to a maximal challenge period of $20 \mathrm{~min}$ and serially diluted prior to plating onto LB medium plus antibiotic as needed. For acid-challenge-survival determination, aliquots were removed at time zero, $10 \mathrm{~min}$, $30 \mathrm{~min}$ and $45 \mathrm{~min}$, and serially diluted prior to plating onto LB medium, plus antibiotic as needed. The percentage survival was calculated as the c.f.u. $\mathrm{ml}^{-1}$ at each time point divided by the c.f.u. $\mathrm{ml}^{-1}$ at time zero (maximum viability), which was typically $3-5 \times 10^{6}$ c.f.u. $\mathrm{ml}^{-1}$.

Assay for expression in MDCK cells. Infection and assay for intracellular $\beta$-galactosidase expression was carried out as described previously (Finlay \& Falkow, 1989; Garcia del Portillo et al., 1992; Spector et al., 1999). Briefly, MadinDarby canine kidney (MDCK) epithelial cells (ATCC CCL34) were grown to confluency in minimum Eagle's medium (MEM) containing 5\% foetal bovine serum (FBS) in 96-well plates $\left(\sim 10^{5}\right.$ cells per well). Monolayers were infected with about $10^{6}$ bacteria, previously grown overnight in LB broth at $37^{\circ} \mathrm{C}$ without shaking. Bacterial infection was performed for $2 \mathrm{~h}$ at $37^{\circ} \mathrm{C}$. Infected epithelial cells were washed three times with PBS, $\mathrm{pH} 7 \cdot 4$, to remove non-adherent bacteria. Infected monolayers were then incubated in the presence of fresh MEM plus $5 \%$ FBS medium containing $100 \mu$ g gentamicin $\mathrm{ml}^{-1}$, to kill any adherent non-internalized bacteria associated with the cell monolayer. Incubation with gentamicin was carried out for the period of $2-4 \mathrm{~h}$ post-infection. The gentamicin concentration was then reduced to $10 \mu \mathrm{g} \mathrm{ml} \mathrm{m}^{-1}$ and the monolayers were incubated for an additional $2 \mathrm{~h}$ (4-6 h postinfection). At $6 \mathrm{~h}$ post-infection, the MDCK monolayers were lysed with $1 \%(\mathrm{v} / \mathrm{v})$ Triton X-100 in PBS $(\mathrm{pH} 7 \cdot 4)$ to release the intracellular bacteria. Viable cell counts were determined for the intracellular bacteria.

A cell lysate was also prepared to measure $\beta$-galactosidase activity in intracellular bacteria. Infected epithelial cells were lysed with $0 \cdot 1 \%(\mathrm{w} / \mathrm{v})$ SDS/chloroform and $\beta$-galactosidase activity was measured using the fluorescent substrate fluorescein di-( $\beta$-D-thiogalactopyranoside) as described previously (Garcia del Portillo et al., 1992).

In addition, $\beta$-galactosidase activity was measured in parallelrun uninfected epithelial cells and subtracted as the background. Extracellular (non-internalized) bacteria after $2 \mathrm{~h}$ incubation with MDCK monolayers were also collected, viable cell counts determined and $\beta$-galactosidase activity measured for comparison with intracellular expression. Intracellular induction was expressed as a ratio between $\beta$-galactosidase activity in internalized and extracellular bacteria.

Virulence assays. Cultures of the $S$. typhimurium strains to be tested were grown overnight in $\mathrm{L}$ broth at $37^{\circ} \mathrm{C}$ without shaking. Cultures were pelleted by centrifugation at $2700 \mathrm{~g}$ in a bench-top centrifuge. The cells were then resuspended in PBS. The OD ${ }_{650}$ was adjusted to 0.93 , which equates to a cell density of approximately $5 \times 10^{8}$ cells $\mathrm{ml}^{-1}$. For the $\mathrm{LD}_{50}$ determinations, serial dilutions were then made in PBS. Bacterial suspensions were administered intra-gastrically to 6-8-week-old female BALB/c mice by oral gavage in a volume of $200 \mu \mathrm{l}$. Mice were observed daily throughout the experiments.

\section{RESULTS}

\section{Sequence analysis of chromosomal DNA adjacent to the MudJ insertion sites of stiA and sti-99}

Two independently isolated strains carrying MudJ (lac) insertions exhibiting C-starvation-induction were identified from a C-starvation-inducible lac-fusion library (Spector et al., 1988, 1999). One of these was designated stiA and was previously characterized (Spector et al., 1986, 1988; Spector, 1990; Spector \& Cubitt, 1992; O’Neal et al., 1994; Seymour et al., 1996). The other was designated sti-99. Both lac fusions were found to be induced during $\mathrm{C}, \mathrm{N}$ and $\mathrm{P}$ starvation in a $\sigma^{\mathrm{S}}$ dependent manner (O’Neal et al., 1994; M. P. Spector, unpublished; reviewed by Loewen \& Hengge-Aronis, 1994). In addition, both are induced when intracellular NAD levels fall to growth-inhibiting concentrations (Spector et al., 1988; M. P. Spector, unpublished). Both are under positive control by relA (i.e. ppGpp) and negative control by cAMP:CRP complex (Spector $\&$ Cubitt, 1992; M. P. Spector, unpublished). Both were also required for long-term starvation survival of $S$. typhimurium (Spector \& Cubitt, 1992; O’Neal et al., 1994; M. P. Spector, unpublished).

Analysis of chromosomal DNA adjacent to the stiA and sti-99:: MudJ (lac) insertions was performed using one or both of two protocols. Originally, the kanamycinresistance gene of the stiA::MudJ (lac) insertion and downstream chromosomal DNA was cloned utilizing the presence of a unique SalI site upstream of the kanamycin-resistance gene in the MudJ vector. A $5 \mathrm{~kb}$ SalI fragment was cloned into pACYC184, to create pSS1, and used as a template for DNA sequence analysis. Chromosomal DNA adjacent to the sti-99:: MudJ (lac) insertion, as well as the stiA:: MudJ (lac) insertion, was amplified using a SP-PCR protocol (Spector et al., 1999) and the DNA sequence was determined. Results of the DNA sequence analysis obtained from the latter protocol is presented in Fig. 1. The sequence data obtained from the pSS1 SalI insert agreed with the sequence obtained from the SP-PCR-amplified fragment presented for stiA in Fig. 1. BLAST(P) searches of the sequences obtained revealed that both were located at different sites within the S. typhimurium homologue of the E. coli 
(c)

(a)

\begin{tabular}{|c|c|c|c|}
\hline narZ & narY & narW & narV \\
\hline 1246 aа & 514 aа 231 aа 226 aа
\end{tabular}

\begin{tabular}{|cccc|}
\hline Insertion & $\begin{array}{c}\text { No. nt } \\
\text { sequenced }\end{array}$ & $\begin{array}{c}\text { Corresponding } \\
\text { E. coli sequence }\end{array}$ & $\begin{array}{c}\text { Percentage } \\
\text { identity }\end{array}$ \\
\hline \multirow{2}{*}{ sti-99 } & 289 & $\begin{array}{c}\text { E. coli narZ nt 1791-2079 } \\
\text { E. coli NarZ aa 598-693 }\end{array}$ & 78 \\
& & 81 \\
stiA & 108 & E. coli narZ nt 3000-3107 & 86 \\
& & E. coli NarZ aa 1001-1035 & 91 \\
\hline
\end{tabular}

(b)

\begin{tabular}{|c|c|c|c|c|c|}
\hline $\begin{array}{l}\text { E.c._narZ_598-647 } \\
\text { ST63_sti-99_deduced }\end{array}$ & $\begin{array}{l}\text { WNRPPRQMNS } \\
\star \star \star \star \star \star \star \star \star \star \star \star\end{array}$ & $\begin{array}{l}\text { TSFFYNHSSQ } \\
\star \star \star \star \star \star \star \star A \star * \star\end{array}$ & $\begin{array}{l}\text { WRYEKVSAQE } \\
\star \star \star \star \star \star L T * \star \star\end{array}$ & $\begin{array}{l}\text { LLSPLADASK } \\
\star \star \star \star \star \star \star * \mathrm{PA} *\end{array}$ & $\begin{array}{l}\text { YSGHLIDFNV } \\
\text { F* } * \star \star \star \star \star \star \star \star\end{array}$ \\
\hline $\begin{array}{l}\text { E.c._narZ_648-693 } \\
\text { ST63_sti-99_deduced }\end{array}$ & $\begin{array}{l}\text { RAERMGWLPS } \\
\star \star \star \star \star \star \star \star \star \star \star \star\end{array}$ & $\begin{array}{l}\text { APQLGRNPLG } \\
\star \star \star \star N L * \star * S\end{array}$ & $\begin{array}{l}\text { IKAEADKAGL } \\
\mathrm{V} * \star S * \star \star \star \star *\end{array}$ & $\begin{array}{l}\text { SPTEFTAQAL } \\
\star A A D Y * V \star \star \star\end{array}$ & $\begin{array}{l}\text { KSGDLR } \\
\star \star \star A I *\end{array}$ \\
\hline $\begin{array}{l}\text { E.c._narZ_1001-1035 } \\
\text { ST66_stiA_deduced }\end{array}$ & $\begin{array}{l}\text { AQPRKIISSP } \\
\star \star \star \star \star \star \star \star \star N *\end{array}$ & $\begin{array}{l}\text { TWSGLESDHV } \\
\star \star \star \star \star \star \star \star E * \star\end{array}$ & $\begin{array}{l}\text { SYNAGYTNVH } \\
\star \star \star \star \star \star \star A * \star \star\end{array}$ & $\begin{array}{l}\text { ELIPPW } \\
\star \star \star \star \star \star\end{array}$ & \\
\hline
\end{tabular}

Fig. 1. Comparison of the DNA and deduced amino acid sequences adjacent to the MudJ insertion sites designated stiA and sti-99 in S. typhimurium with the E. coli narZ DNA and deduced amino acid sequences (GenBank entry X17110). (a) Schematic representation of the E. coli narZYWV operon organization and deduced size of each protein. (b) Direct comparison of the primary sequence of the $E$. coli narZ deduced amino acids 598-693 and amino acids 1001-1035 with the deduced amino acid sequences adjacent to the sti-99::MudJ insertion site (ST63_sti-99_deduced) and stiA::MudJ insertion site (ST66_stiA_deduced), respectively. Asterisks (*) indicate shared identical amino acid residues; differences in deduced amino acid residues are indicated for the Salmonella sequence. (c) Table showing the number of nucleotides sequenced adjacent to each insertion and the corresponding $E$. coli narZ DNA and deduced amino acid sequence to which it was compared along with the percentage identity they share.

Table 2. Nitrate reductase activity in wild-type, narGHIJ knockout and narZYWV knockout mutant strains of S. typhimurium grown under various inducing and non-inducing conditions

Values shown are means \pm SEM of at least three separate experiments.

\begin{tabular}{|c|c|c|c|c|}
\hline \multirow[t]{2}{*}{ Strain } & \multirow[t]{2}{*}{ Pertinent genotype } & \multicolumn{3}{|c|}{ NR activity (NR units) } \\
\hline & & $\begin{array}{l}\text { Aerobiosis, no nitrate, } \\
\text { exponential phase }\end{array}$ & $\begin{array}{c}\text { Anaerobiosis, } 50 \mathrm{mM} \\
\text { nitrate, exponential phase }\end{array}$ & $\begin{array}{c}\text { Aerobiosis, no } \\
\text { nitrate, } 3 \mathrm{~h} \text { C starved }\end{array}$ \\
\hline SL1344 & narZYWV $V^{+}$narGHIJ ${ }^{+}$ & $0 \cdot 24 \pm 0 \cdot 01$ & $3 \cdot 44 \pm 0 \cdot 33$ & $1 \cdot 21 \pm 0 \cdot 21$ \\
\hline SMS643 & narZYWV $V^{+}$arGHIJ1715::MudJ & $0 \cdot 23 \pm 0 \cdot 02$ & $0 \cdot 22 \pm 0 \cdot 01$ & $1 \cdot 15 \pm 0 \cdot 15$ \\
\hline ST66 & narZ1:: MudJ narGHIJ ${ }^{+}$ & $0 \cdot 24 \pm 0 \cdot 03$ & $2 \cdot 82 \pm 0 \cdot 55$ & $0 \cdot 21 \pm 0 \cdot 11$ \\
\hline
\end{tabular}

narZ gene sequence (GenBank entry X17110). The $\mathrm{MudJ}$ (lac) insertion designated sti-99 was found to be proximal (deduced amino acid 597 of 1246) to the deduced translational start site, followed by the more distal MudJ (lac) insertion designated stiA (deduced amino acid 1000 of 1246). As a result, the stiA and sti-99 insertions were renamed narZ1 and narZ2, respectively, to reflect these findings.

\section{Phenotypic evidence to support the identification of the stiA locus as narZ(YWV)}

To support our DNA sequence analyses indicating that the stiA/sti-99 locus was identical to the nar $Z$ gene, phenotypic characterization was carried out. The nar $Z$ gene is the first gene of the narZYWV operon which encodes a previously described cryptic and constitutive NR activity, NR-Z. Unlike the major NR of E. coli and Salmonella, NR-A, encoded by the narGHJI operon (reviewed by Gennis \& Stewart, 1996), NR-Z production is not anaerobically induced and is not nitrate responsive. The data presented in Table 2 illustrate that there are, at least, two detectable NR activities in $S$. typhimurium SL1344, one anaerobiosis and nitrate responsive, and the other C-starvation inducible. As shown in Table 2, the anaerobiosis- and nitrateresponsive NR activity was eliminated by the $\operatorname{nar} G(H J I)$ knock-out insertion mutation but not by narZ1 knockout insertion mutation (data are shown for the narZ1 insertion mutation but similar data were obtained for 
Table 3. Role of Fnr in narZYWV operon expression in S. typhimurium

Values are means \pm SEM of at least three separate experiments.

\begin{tabular}{|c|c|c|c|c|}
\hline \multirow[t]{2}{*}{ Strain } & \multirow[t]{2}{*}{ Pertinent genotype } & \multicolumn{3}{|c|}{$\beta$-Galactosidase activity (Miller units) } \\
\hline & & $\begin{array}{c}\text { Aerobiosis, } \\
\text { exponential phase }\end{array}$ & $\begin{array}{c}\text { Anaerobiosis, } \\
\text { exponential phase }\end{array}$ & $\begin{array}{l}\text { Aerobiosis, } \\
\text { 3h C starved }\end{array}$ \\
\hline ST66 & narZ1::lac & $9 \cdot 88 \pm 1 \cdot 65$ & $0 \cdot 18 \pm 0 \cdot 25$ & $97 \cdot 59 \pm 37 \cdot 03$ \\
\hline SMS575 & narZ1::lac fnr:: Tn10 & $25 \cdot 25 \pm 3 \cdot 85$ & $13 \cdot 13 \pm 1 \cdot 33$ & $102 \cdot 90 \pm 21 \cdot 32$ \\
\hline
\end{tabular}

(a) Exponential-phase cells (b) 5 h C-starved cells

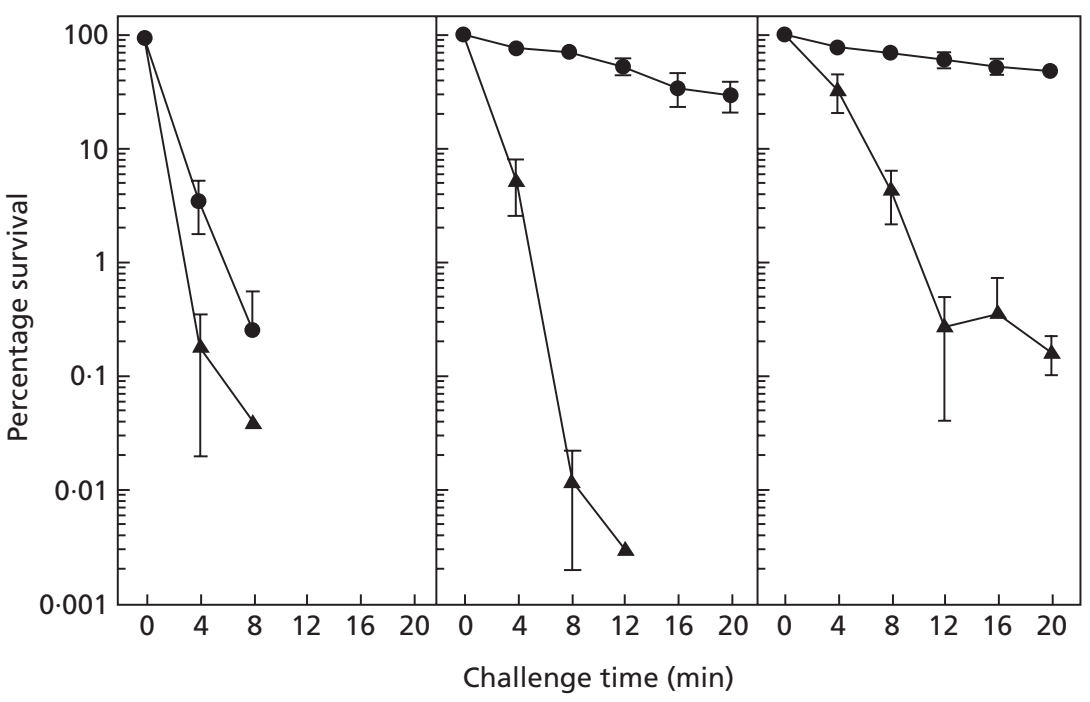

(c) $24 \mathrm{~h} \mathrm{C}$-starved cells

Fig. 2. Role of NR-Z in C-starvationinducible thermotolerance. Wildtype (O) and narZ1::lac mutant ( $\boldsymbol{\Delta})$ cells were grown aerobically to exponential-phase (a) and were Cstarved for $5 \mathrm{~h} \mathrm{(b)} \mathrm{and} 24 \mathrm{~h}$ (c) prior to being challenged at $55^{\circ} \mathrm{C}$ for a maximum of $20 \mathrm{~min}$. Values represent means \pm SEM of at least three separate experiments. the narZ2 knockout-insertion mutation) while the reverse was found for the C-starvation-inducible NR activity. Since the narZ1(stiA): : lac fusion and mutation was previously characterized, it was employed for the analyses performed in this study (unless otherwise indicated).

The results presented in Table 3 further support that the stiA/sti-99 insertions are in the Salmonella narZ(YWV) homologue. Previous studies in E. coli found that NR-Z activity is repressed anaerobically by the $f n r$ gene product, Fnr (Iobbi-Nivol et al., 1990). We found that an fnr knock-out mutation resulted in the derepression of narZ1::lac expression in anaerobically growing cells (compare anaerobiosis, exponential-phase ST66 and SMS575 in Table 3) to about the level observed in aerobically growing wild-type cells (compare anaerobiosis, exponential-phase SMS575 with aerobiosis, exponential-phase ST66 in Table 3). The fnr mutation also led to an approximately $2 \cdot 5$-fold increase in narZ1: : lac basal expression in aerobically growing cells (compare aerobiosis, exponential-phase ST66 and SMS575 in Table 3). Thus, the S. typhimurium nar$Z Y W V$ operon is repressed by Fnr during anaerobiosis as well as during aerobiosis. However, the $f n r$ mutation did not affect the level to which narZ(YWV) was induced during $\mathrm{C}$ starvation (compare aerobiosis, $3 \mathrm{~h}$ C-starved ST66 and SMS575 in Table 3).

\section{Role of the narZ(YWV) operon in C-starvation- inducible thermotolerance}

We previously reported that the stiA locus was required for long-term-starvation survival and $\mathrm{H}_{2} \mathrm{O}_{2}$-inducible $\mathrm{H}_{2} \mathrm{O}_{2}$ resistance but it did not affect C-starvationinducible $\mathrm{H}_{2} \mathrm{O}_{2}$ resistance (Spector \& Cubitt, 1992; Seymour et al., 1996). We wanted to test whether it was also required for heat-shock and C-starvation-inducible thermotolerance. Results from subsequent experiments showed that the $\operatorname{nar} Z(Y W V)$ operon is required for thermotolerance generated in both $5 \mathrm{~h}$ and $24 \mathrm{~h} \mathrm{C}$ starved cells, compared to similarly starved wild-type cells (Fig. 2). The $5 \mathrm{~h} \mathrm{C}$-starved nar $Z$ mutant survived to about the same extent as exponential-phase wild-type or nar $Z$ mutant cells (compare Fig. $2 \mathrm{a}$ and b) and all were clearly more heat sensitive than $5 \mathrm{~h}$ C-starved wild-type cells. Although $24 \mathrm{~h}$ C-starved nar $Z$ mutant cells survived thermal challenge better than $5 \mathrm{~h}$ C-starved nar $Z$ mutant cells, they were still significantly more heat sensitive than $24 \mathrm{~h}$ C-starved wild-type cells (Fig. 2c). Similar results were found for an rpoS mutant, with the 

(a) Exponential-phase cells

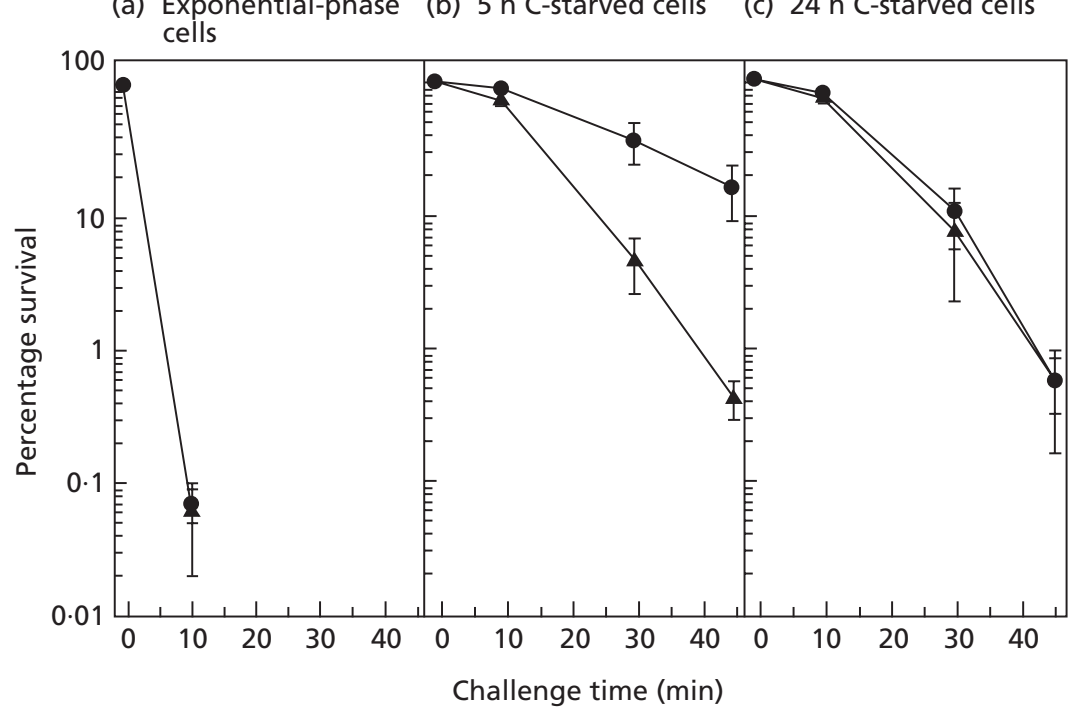

Fig. 3. Role of NR-Z in C-starvationinducible acid tolerance. Wild-type (O) and narZ1::lac mutant ( $\boldsymbol{\Delta})$ cells were grown aerobically to exponential phase (a) and were $C$ starved for $5 \mathrm{~h} \mathrm{(b)}$ and $24 \mathrm{~h} \mathrm{(c)} \mathrm{prior} \mathrm{to} \mathrm{being}$ challenged at $\mathrm{pH} 2 \cdot 8$ for a maximum of $45 \mathrm{~min}$. Values represent means \pm SEM of at least three separate experiments. exception that there was no significant difference between exponential-phase, $5 \mathrm{~h}$ C-starved or $24 \mathrm{~h} \mathrm{C}$ starved cells in terms of thermotolerance generated (data not shown).

Interestingly, the narZ knock-out mutation had no effect on heat-shock-inducible thermotolerance in exponential-phase cells compared to the wild-type strain (data not shown). In contrast, exponential-phase rpoS mutant cells failed to generate a heat-shock-inducible thermotolerance response (data not shown). Thus, NR$\mathrm{Z}$ appears to be required for C-starvation-inducible thermotolerance but not adaptive heat-shock-inducible thermotolerance.

\section{Role of the narZ(YWV) operon in C-starvation- inducible acid tolerance}

We also wanted to determine whether narZ $(Y W V)$ is required for C-starvation-inducible acid tolerance. As shown in Fig. 3, 5 h C-starved wild-type cells were more tolerant than $24 \mathrm{~h}$ C-starved wild-type cells to a $45 \mathrm{~min}$ pH 2.8 challenge but both were significantly more acid tolerant than exponential-phase cells, which were undetectable after only $10 \mathrm{~min}$ at $\mathrm{pH} 2 \cdot 8$. Interestingly, introduction of a narZ1 knock-out mutation into wildtype cells reduced acid tolerance generated in $5 \mathrm{~h} \mathrm{C}$ starved cells by some 40-50-fold to about the level observed in $24 \mathrm{~h}$ C-starved cells (Fig. 3b, c). However, no significant difference was observed in the level of acid tolerance generated in $24 \mathrm{~h}$ C-starved nar $Z$ mutant cells compared to $24 \mathrm{~h} \mathrm{C}$-starved wild-type cells (Fig. 3c). In comparison, an rpoS mutation had a much more dramatic effect on acid tolerance generated in both $5 \mathrm{~h}$ C-starved and $24 \mathrm{~h} \mathrm{C}$-starved cells (data not shown) in agreement with similar findings reported by Lee et al. (1994). Thus, the narZYWV operon is required for acid tolerance generated in $5 \mathrm{~h}$ C-starved cells but not $24 \mathrm{~h} \mathrm{C}$ starved cells. The reason why the loss of NR-Z reduces acid tolerance in $5 \mathrm{~h} \mathrm{C}$-starved cells but not $24 \mathrm{~h} \mathrm{C}$ starved cells is unclear at this time. It may indicate that
NR-Z interacts with (an)other function(s), or other acidtolerance factors are expressed, in $5 \mathrm{~h}$ C-starved cells which are then lost as cells continue to starve. It is possible that NR-Z may also disappear over this time period but previous studies show that narZ1(stiA)::lac is still transcribed at a relatively high level in $24 \mathrm{~h} \mathrm{C}$ starved cells (Spector et al., 1988).

The narZ knock-out mutation did not have an effect on acid-shock-inducible acid tolerance generated in exponential-phase cells compared to the wild-type strain (data not shown). Similar to the heat-shock scenario, exponential-phase rpoS mutant cells failed to generate an acid-shock-inducible acid tolerance (Lee et al., 1994). Thus, NR-Z appears to be required for C-starvationinducible acid tolerance but not adaptive acid-shockinducible acid tolerance.

\section{Expression of the narZ(YWV) operon within cultured MDCK epithelial cells and during growth in ISM}

S. typhimurium is a facultative intracellular pathogen (Finlay \& Falkow, 1989); thus, it is useful to know whether a specific function is expressed in the host environment. This information can provide important insights into the intracellular environment as well as potential roles in pathogenesis (Mahan et al., 1995; Valdivia \& Falkow, 1997). To determine whether narZYWV is expressed intracellularly within MDCK cells, strains ST66 and ST63 were allowed to infect MDCK epithelial cells. At $6 \mathrm{~h}$ post-infection, intracellular bacteria were collected and $\beta$-galactosidase activity was measured and compared to the activity in extracellular bacteria. Results from such experiments indicate that narZYWV was induced $19 \cdot 58 \pm 5 \cdot 72$-fold (mean \pm sEM, $n=4$ ) within MDCK epithelial cells. Furthermore, the narZ1 : : lac fusion was found to be induced $15 \cdot 8 \pm 0 \cdot 82$ fold (mean \pm SEM, $n=3$ ) during exponential-phase growth in ISM (Wilson et al., 1997) compared to LB broth. ISM was designed to mimic the intracellular milieu of cells and so induction in ISM supports the 
findings that $\mathrm{NR}-\mathrm{Z}$ is expressed within MDCK epithelial cells. The induction ratios observed under both conditions were comparable to the $\sim 10$-fold induction seen in $3 \mathrm{~h}$ C-starved cells compared to exponentially growing cells but much less than the almost 55 -fold induction seen with exponential-phase cells grown aerobically versus anaerobically (Table 3 ). These results support a model that the intracellular environment seen by Salmonella inside MDCK epithelial cells, and perhaps other epithelial cells, generates similar (or cross-reacting) signals to those signals known to induce nar $Z Y W V$ expression.

\section{Effect of the narZYWV knock-out mutation on the oral $L_{50}$ of SL1344 in the mouse virulence model}

Since narZYWV was induced intracellularly, we tested to see whether the narZ1 mutation had an effect on $S$. typhimurium virulence in the mouse virulence model. For this, SL1344 and its narZ1 derivative (ST66) were each given by oral gavage to separate groups of five $\mathrm{BALB} / \mathrm{c}$ mice to determine the relative $\mathrm{LD}_{50}$ values. Mice were monitored for $28 \mathrm{~d}$. The $\mathrm{LD}_{50}$ values were calculated to be approximately $10^{4 \cdot 5}$ for SL1344 and $10^{5 \cdot 6}$ for ST66 (a little more than 10-fold higher). Thus, the narZ knock-out mutant exhibited a higher $\mathrm{LD}_{50}$ compared to SL1344 but did not completely attenuate virulence when delivered orally in the mouse virulence model.

\section{DISCUSSION}

In this study, we report that two independently isolated MudJ (lac) insertions, designated stiA and sti-99, identified from our library of C-starvation-inducible $\mathrm{MudJ}(\mathrm{lac}$ ) transcriptional fusions are located at different sites within the same gene. Sequence analysis of chromosomal DNA adjacent to each insertion site showed that both lie within the S. typhimurium homologue of the E. coli narZ gene (GenBank entry X17110) exhibiting on average $>85 \%$ identity at the amino acid level (Fig. 1). As mentioned above, the nar $Z$ gene is the first gene of the narZYWV operon encoding NR-Z, previously believed to be both cryptic and constitutive. The narZ(YWV) locus of both E. coli and Salmonella exhibits a high degree of homology at both the DNA and amino acid level to the major anaerobiosis- and nitrateresponsive NR, NR-A, encoded by the narGHJI operon. NR-Z was proposed to be constitutive since it was not induced under anaerobic conditions in the presence of nitrate (Iobbi-Nivol et al., 1990; reviewed by Gennis \& Stewart, 1996). Results from this study confirm that the narZYWV encoded NR-Z is not anaerobiosis- or nitrate-responsive but is induced during $C$ starvation (Table 2). In addition, we present data that Salmonella nar $Z Y W V$ expression is repressed under anaerobiosis by Fnr, supporting a previous finding that nar $Z Y W V$ in E. coli is repressed anaerobically by Fnr (Iobbi-Nivol et al., 1990; Table 3). Thus, we clearly demonstrate that the previously characterized stiA locus is identical to the narZYWV operon.
The finding that stiA is narZYWV has some interesting and important implications. The regulation of the stiA locus has been studied extensively (Spector et al., 1986, 1988; Spector, 1990; Spector \& Cubitt, 1992; O’Neal et al., 1994; Seymour et al., 1996; reviewed by Spector \& Foster, 1993; Spector, 1998). Results from this and previous studies show that $\operatorname{nar} Z(Y W V)$ is: (a) induced during $\mathrm{P}$ and $\mathrm{N}$ starvation as well as $\mathrm{C}$ starvation, $(\mathrm{b}) \sigma^{\mathrm{S}}$ dependent, (c) positively regulated by (p)ppGpp in a relA-dependent manner, (d) repressed by cAMP:CRP in exponential-phase cells, (e) $\mathrm{H}_{2} \mathrm{O}_{2}$ inducible and repressed by OxyR (reduced-form) in exponential-phase cells in the absence of exogenous $\mathrm{H}_{2} \mathrm{O}_{2}$ and (f) repressed by Fnr under anaerobiosis as well as aerobiosis (Table 3). Therefore, $N R-Z$ is anything but constitutive and, in fact, exhibits very complex regulation, foretelling its role in multiple stress responses.

Since NR-Z was not anaerobiosis or nitrate responsive it was originally proposed to be a basal constitutive NR activity that could be used by the cell during the transition to anaerobiosis in the presence of nitrate to generate enough energy to allow for the synthesis of the major anaerobiosis- and nitrate-responsive NR-A activity. This was a reasonable hypothesis given the available data (Barrett \& Riggs, 1982; reviewed by Gennis \& Stewart, 1996). However, in light of its now realized complex regulation and the fact that it is required for long-term-starvation survival, $\mathrm{H}_{2} \mathrm{O}_{2}$ inducible $\mathrm{H}_{2} \mathrm{O}_{2}$ resistance (Spector \& Cubitt, 1992; Seymour et al., 1996), C-starvation-inducible thermotolerance (Fig. 2) and acid tolerance (Fig. 3), this relatively simplistic role seems incomplete at best.

The exact physiological role of NR-Z activity is unclear at this time. However, the facts that the stiA and sti-99 designated fusions were identified from two different screens for stress-responsive genetic loci, exhibit complex global and stress regulation and are expressed within MDCK epithelial cells suggest a key role in starved- and stressed-cell physiology. Furthermore, the probability that narZYWV resulted from a duplication of narGHJI in a common ancestor of E. coli and Salmonella and the fact that it has been functionally conserved while its regulation has diverged from that of NR-A support the hypothesis of a key physiological role for the NR-Z activity in the cell at some time during its life cycle (Barrett \& Riggs, 1982; Bonnefoy \& DeMoss, 1994; Gennis \& Stewart, 1996).

The reason why NR-Z is necessary for resistance to $\mathrm{H}_{2} \mathrm{O}_{2}$ only in growing cells exposed to exogenously added $\mathrm{H}_{2} \mathrm{O}_{2}$ but is needed for acid and thermal tolerance only in C-starved cells probably lies in its as yet unidentified physiological function and the redundancy that is common among stress response functions. The fact that $\sigma^{\mathrm{S}}$ is needed not only for stress-specific adaptive stress responses but also for starvation-induced stress responses supports the idea of redundancy.

Other respiratory enzymes or components have also been associated with stationary-phase and stressed-cell physiology. In E. coli, mutants in NADH dehydrogenase 
I are unable to develop the GASP (growth advantage in stationary-phase) phenotype. The GASP phenotype is thought to result from mutations that occur in stationary-phase cells (i.e. prolonged growth in LB broth medium) that provide a growth advantage to the cell, allowing them to take over the stationary-phase culture (Zambrano et al., 1993; Zambrano \& Kolter, 1993). In Salmonella, mutants in the energy-conserving NADH dehydrogenase, i.e. nuo mutants, exhibit defective energy-dependent proteolysis during $C$ starvation (Archer et al., 1993). In E. coli, both the byaABCDEF (hydrogenase I) and the $c b d A B$ (cytochrome $b d$-II oxidase; also known as $c y x A B$ ) operons are anaerobiosis inducible, $\mathrm{C}$ - and $\mathrm{P}$-starvation inducible, and stationaryphase inducible in rich medium. Furthermore, the induction of both bya and $c b d A B$ upon entry into stationary-phase is under $\sigma^{\mathrm{S}}$ control. Also, the Cstarvation induction of bya is $\sigma^{\mathrm{s}}$ dependent while the Cstarvation induction of $c b d A B$ is indirectly $\sigma^{\mathrm{S}}$ regulated through the appY gene (Atlung et al., 1997). Interestingly, E. coli cells deficient in another cytochrome $b d$ oxidase, encoded by $c y d A B$, are hypersensitive to $\mathrm{H}_{2} \mathrm{O}_{2}$ and high temperatures (Wall et al., 1992; Goldman et al., 1996), similar to narZYWV mutants. Recently, the cydAB-encoded cytochrome $b d$ oxidase has been implicated in intracellular survival and virulence of Shigella flexneri (Way et al., 1999). Thus, there is some precedent for a link between respiratory enzymes, stress responses and survival, as well as virulence potential.

It would seem unlikely that NR-Z would have a role in respiration and energy production in the starved or stressed cell. The reason for this is that its regulation and roles in stress resistance have been studied in well aerated cultures where oxygen should be the much preferred electron acceptor and nitrate should be scarce at best, since none has been added to the culture media. However, the possibility that it may use an alternative electron acceptor(s), e.g. nitric oxide or NO, has not been ruled out and is under study in our laboratory.

NR-Z may be important in the defence of Salmonella against so-called bacterial ageing (Nyström et al., 1996; Dukan \& Nyström, 1998). Nyström and colleagues present a convincing case that oxidation of proteins is a key correlate to cell ageing and possibly cell death in stationary-phase cells. They also demonstrate that stationary-phase induced protein oxidation is enhanced in $o x y R$ and $r p o S$ mutant cells. In this context, it is interesting that narZYWV expression is $\sigma^{\mathrm{s}}$ dependent and $\mathrm{H}_{2} \mathrm{O}_{2}$ inducible. As such, NR-Z may play a role in detoxifying reactive oxygen species, or other byproducts, that might be generated under conditions such as long-term starvation, presence of $\mathrm{H}_{2} \mathrm{O}_{2}$, high temperature or acidic $\mathrm{pH}$. Its membrane location suggests that in such a role it may be involved in the repair of membrane damage or detoxification of products formed during aerobic metabolism (i.e. electron transport) at the inner membrane under various stress conditions. However, this has yet to be demonstrated. Studies designed to dissect the complex regulatory region of narZYWV and to determine its function(s) during starvation and stress conditions are currently under way in our laboratory.

\section{ACKNOWLEDGEMENTS}

The authors would like to thank Dr Julio Turrens for technical assistance and helpful discussions, Marc Woodland for automated sequencing help, and Paul Everest, Gill Douce and the staff of Central Biological Services for assistance with in vivo studies. We would also like to thank Dr Paul Gulig for supplying intracellular salts medium.

Portions of the work presented here were funded by grants from the National Institutes of Health (NIH) grant no. GM47628-01 and the University of South Alabama Research Council (to M.P.S.), NIH grant no. GM48017 (to J. W.F.) and the Medical Research Council of Canada (to B.B.F.). M. J.P. and G.D. would also like to thank the Wellcome Trust for supporting a Research Leave Fellowship for M. J.P.

\section{REFERENCES}

Archer, C. D., Wang, X. \& Elliott, T. (1993). Mutants defective in the energy-conserving NADH dehydrogenase of Salmonella typhimurium identified by a decrease in energy-dependent proteolysis after carbon starvation. Proc Natl Acad Sci USA 90, 9877-9881.

Atlung, T., Knudsen, K., Lotte, H. \& Brøndsted, L. (1997). Effects of $\sigma^{\mathrm{S}}$ and the transcriptional activator AppY on induction of the Escherichia coli bya and cbdAB-appA operons in response to carbon and phosphate starvation. J Bacteriol 179, 2141-2146.

Babior, B. M. (1992). The respiratory burst oxidase. Adv Enzymol Relat Areas Mol Biol 65, 49-95.

Barrett, E. L. \& Riggs, D. L. (1982). Evidence for a second nitrate reductase activity that is distinct from the respiratory enzyme in Salmonella typhimurium. J Bacteriol 150, 563-571.

Blasco, F., lobbi, C., Ratouchniak, J., Bonnefoy, V. \& Chippaux, M. (1990). Nitrate reductases of Escherichia coli: sequence of the second nitrate reductase and comparison with that encoded by the narGHJI operon. Mol Gen Genet 222, 104-111.

Bonnefoy, V. \& DeMoss, J.A. (1994). Nitrate reductases in Escherichia coli. Antonie Leeuwenhoek 66, 47-56.

Brown, M. R. W. \& Williams, P. (1985). The influence of environment on envelope properties affecting survival of bacteria in infections. Annu Rev Microbiol 39, 527-556.

Cashel, M. Gentry, D. R., Hernandez, V. J. \& Vinella, D. (1996). The stringent response. In Escherichia coli and Salmonella: Cellular and Molecular Biology, 2nd edn, pp. 1458-1496. Edited by F. C. Neidhardt and others. Washington, DC: American Society for Microbiology.

Castilho, B. A., Olfson, P. \& Casadaban, M. J. (1984). Plasmid insertion mutagenesis and lac gene fusions with mini-Mu bacteriophage transposons. J Bacteriol 158, 488-495.

Chan, R. K., Botstein, D., Watanabe, T. \& Ogata, Y. (1972). Specialized transduction of tetracycline resistance by phage P22 in Salmonella typhimurium. II. Properties of a high transducing lysate. Virology 50, 883-898.

Davis, R. W., Botstein, D. \& Roth, J. R. (1980). Advanced Bacterial Genetics. Cold Spring Harbor, NY: Cold Spring Harbor Laboratory.

Dukan, S. \& Nyström, T. (1998). Bacterial senescence: stasis results in increased and differential oxidation of cytoplasmic proteins leading to developmental induction of the heat shock regulon. Genes Dev 12, 3431-3441. 
Fang, F. C., Libby, S. J., Buchmeier, N. A., Loewen, P. C., Switala, J., Harwood, J. \& Guiney, D. G. (1992). The alternative $\sigma$ factor KatF (RpoS) regulates Salmonella virulence. Proc Natl Acad Sci USA 89, 11978-11982.

Finlay, B. B. \& Falkow, S. (1989). Salmonella as an intracellular parasite. Mol Microbiol 3, 1833-1841.

Foster, J. W. \& Spector, M. P. (1986). Phosphate-starvation regulon of Salmonella typhimurium. J Bacteriol 166, 666-669.

Foster, J. W. \& Spector, M. P. (1995). How Salmonella survive against the odds. Annu Rev Microbiol 49, 145-174.

Garcia del Portillo, F., Foster, J. W., Maguire, M. E. \& Finlay, B. B. (1992). Characterization of the micro-environment of Salmonella typhimurium-containing vacuoles within MDCK epithelial cells. Mol Microbiol 6, 3289-3297.

Gennis, R. B. \& Stewart, V. (1996). Respiration. In Escherichia coli and Salmonella: Cellular and Molecular Biology, 2nd edn, pp. 217-261. Edited by F. C. Neidhardt and others. Washington, DC: American Society for Microbiology.

Goldman, B. S., Gabbert, K. K. \& Kranz, R. G. (1996). The temperature-sensitive growth and survival phenotypes of Escherichia coli $c y d D C$ and $c y d A B$ strains are due to deficiencies in cytochrome $b d$ and are corrected by exogenous catalase and reducing agents. J Bacteriol 178, 6348-6351.

Harder, W. \& Dijkhuizen, L. (1983). Physiological responses to nutrient limitation. Annu Rev Microbiol 37, 1-23.

Hengge-Aronis, R. (1993). The role of rpoS in early stationaryphase gene regulation in Escherichia coli K12. In Starvation in Bacteria, pp. 171-200. Edited by S. Kjelleberg. New York: Plenum.

Hengge-Aronis, R. (1996). Regulation of gene expression during entry into stationary phase. In Escherichia coli and Salmonella: Cellular and Molecular Biology, 2nd edn, pp. 1497-1512. Edited by F. C. Neidhardt and others. Washington, DC: American Society for Microbiology.

Hoiseth, S. K. \& Stocker, B. A. D. (1981). Aromatic-dependent Salmonella typhimurium are non-virulent and effective as live vaccines. Nature 291, 238-239.

lobbi-Nivol, C., Santini, C. L., Blasco, F. \& Giordano, G. (1990). Purification and further characterization of the second nitrate reductase of Escherichia coli K-12. Eur J Biochem 188, 679-687.

Jenkins, D. E., Schultz, J. E. \& Matin, A. (1988). Starvation-induced cross-protection against heat or $\mathrm{H}_{2} \mathrm{O}_{2}$ challenge in Escherichia coli. J Bacteriol 170, 3910-3914.

Koch, A. L. (1971). The adaptive response of Escherichia coli to a feast and famine existence. Adv Microb Physiol 6, 147-217.

Lange, R. \& Hengge-Aronis, R. (1991). Identification of a central regulator of stationary-phase gene expression in Escherichia coli. Mol Microbiol 5, 49-59.

Lee, I. S., Slonczewski, J. L. \& Foster, J. W. (1994). A low-pH inducible stationary-phase acid tolerance response in Salmonella typhimurium. J Bacteriol 176, 1422-1426.

Loewen, P. C. \& Hengge-Aronis, R. (1994). The role of the sigma factor $\sigma^{\mathrm{s}}(\mathrm{KatF})$ in bacterial global regulation. Annu Rev Microbiol 48, 53-80.

McCann, M. P., Fraley, C. D. \& Matin, A. (1991). The putative $\sigma$ factor KatF has a central role in development of starvationmediated general resistance in Escherichia coli. J Bacteriol 173, 4188-4194.

McLeod, G. I. \& Spector, M. P. (1996). Starvation- and stationaryphase-induced resistance to the antimicrobial peptide polymyxin B in Salmonella typhimurium is $\operatorname{RpoS}\left(\sigma^{\mathrm{S}}\right)$ independent and occurs through both phoP-dependent and -independent pathways. $J$ Bacteriol 178, 3683-3688.

Mahan, M. J., Tobias, J. W., Slauch, J. M., Hanna, P. C., Collier, J. R. \& Mekalanos, J. J. (1995). Antibiotic based selection for bacterial genes that are specifically induced during infection of a host. Proc Natl Acad Sci USA 92, 669-673.

Maloy, S. R. (1990). Experimental Techniques in Bacterial Genetics. Boston, MA: Jones \& Bartlett.

Matin, A. (1991). The molecular basis of carbon-starvationinduced general resistance in Escherichia coli. Mol Microbiol 5, $3-10$.

Miller, J. H. (1972). Experiments in Molecular Genetics. Cold Spring Harbor, NY: Cold Spring Harbor Laboratory.

Miller, J. H. (1992). A Short Course in Bacterial Genetics: a Laboratory Manual and Handbook for Escherichia coli and Related Bacteria. Cold Spring Harbor, NY : Cold Spring Harbor Laboratory.

Moriarty, D. J. W. \& Bell, R. T. (1993). Bacterial growth and starvation in aquatic environments. In Starvation in Bacteria, pp. 25-53. Edited by S. Kjelleberg. New York: Plenum.

Morita, R. Y. (1988). Bioavailability of energy and its relationship to growth and starvation survival in nature. Can J Microbiol 34, 436-441.

Mulvey, M. R. \& Loewen, P. C. (1989). Nucleotide sequence of katF of Escherichia coli suggests KatF protein is a novel $\sigma$ transcription factor. Nucleic Acids Res 17, 9979-9991.

Neidhardt, F. C., Bloch, P. L. \& Smith, D. F. (1974). Culture medium for enterobacteria. J Bacteriol 119, 736-747.

Nyström, T., Larsson, C. \& Gustafsson, L. (1996). Bacterial defense against aging: role of the Escherichia coli ArcA regulator in gene expression, readjusted energy flux and survival during stasis. EMBO J 15, 3219-3228.

O’Neal, C. R., Gabriel, W. M., Turk, A. K., Libby, S. J., Fang, F. C. \& Spector, M. P. (1994). RpoS is necessary for both the positive and negative regulation of starvation survival genes during phosphate, carbon, and nitrogen starvation in Salmonella typhimurium. J Bacteriol 176, 4610-4616.

Parks, C. L, Chang, L. S. \& Shenk, T. (1991). A polymerase chain reaction mediated by a single primer: cloning of genomic sequences adjacent to a serotonin receptor protein coding region. Nucleic Acids Res 19, 7155-7160.

Rosenthal, A., Coutelle, O. \& Craxton, M. (1993). Large-scale production of DNA sequencing template by microtitre format PCR. Nucleic Acids Res 21, 173-174.

Roszak, D. B. \& Colwell, R. R. (1987). Survival strategies of bacteria in the natural environment. Microbiol Rev 51, 365-379.

Seymour, R. L., Mishra, P. V., Khan, M. A. \& Spector, M. P. (1996). Essential roles of core starvation-stress response loci in carbonstarvation-inducible cross-resistance and hydrogen peroxideinducible adaptive resistance to oxidative challenge in Salmonella typhimurium. Mol Microbiol 20, 497-505.

Spector, M. P. (1990). Gene expression in response to multiple nutrient-starvation conditions in Salmonella typhimurium. FEMS Microbiol Ecol 74, 175-184.

Spector, M. P. (1998). The starvation-stress response (SSR) of Salmonella. Adv Microb Physiol 40, 233-279.

Spector, M. P. \& Cubitt, C. L. (1992). Starvation-inducible loci of Salmonella typhimurium: regulation and roles in starvation survival. Mol Microbiol 6, 1467-1476.

Spector, M. P. \& Foster, J. W. (1993). Starvation-stress response (SSR) of Salmonella typhimurium: gene expression and survival 
during nutrient starvation. In Starvation in Bacteria, pp. 201-224. Edited by S. Kjelleberg. New York: Plenum.

Spector, M. P., Aliabadi, Z., Gonzalez, T. \& Foster, J. W. (1986). Global control in Salmonella typhimurium: two-dimensional gel electrophoretic analysis of starvation-, anaerobiosis-, and heatshock-inducible proteins. J Bacteriol 168, 420-424.

Spector, M. P., Park, Y. K., Tirgari, S., Gonzalez, T. \& Foster, J. W. (1988). Identification and characterization of starvation-regulated genetic loci in Salmonella typhimurium by using Mud-directed lacZ operon fusions. J Bacteriol 170, 345-351.

Spector, M. P., DiRusso, C. C., Pallen, M. J., Garcia del Portillo, F., Dougan, G. \& Finlay, B. B. (1999). The medium-/long-chain fatty acyl-CoA dehydrogenase $(\mathrm{fadF})$ gene of Salmonella typhimurium is a phase 1 starvation-stress response (SSR) locus. Microbiology $145,15-31$.

Storz, G. \& Altuvia, S. (1994). OxyR regulon. Methods Enzymol 234, 217-223.

Storz, G., Tartaglia, L. A. \& Ames, B. N. (1990). Transcriptional regulator of oxidative stress-inducible genes: direct activation by oxidation. Science 248, 189-194.

Tanaka, K., Takayanagi, Y., Fujita, N., Ishihama, A. \& Takahashi, H. (1993). Heterogeneity of the principal $\sigma$ factor in Escherichia coli: the rpoS gene product, $\sigma^{38}$, is a second principal $\sigma$ factor of RNA polymerase in stationary-phase Escherichia coli. Proc Natl Acad Sci USA 90, 3511-3515.
Valdivia, R. H. \& Falkow, S. (1997). Probing bacterial gene expression within host cells. Trends Microbiol 5, 360-363.

Wall, D., Delaney, J. M., Fayet, O., Lipinska, B., Yamamoto, T. \& Georgopoulos, C. (1992). arcA-dependent thermal regulation and extragenic suppression of the Escherichia coli cytochrome $d$ operon. J Bacteriol 174, 6554-6562.

Way, S. S., Sallustio, S., Magliozzo, R. S. \& Goldberg, M. B. (1999). Impact of either increased or decreased levels of cytochrome bd expression on Shigella flexneri virulence. J Bacteriol 181, 1229-1237.

Wilson, J. A., Doyle, T. J. \& Gulig, P. A. (1997). Exponential-phase expression of $s p v A$ of the Salmonella typhimurium virulence plasmid: induction in intracellular salts medium and intracellularly in mice and cultured mammalian cells. Microbiology 143, 3827-3839.

Zambrano, M. M. \& Kolter, R. (1993). Escherichia coli mutants lacking NADH dehydrogenase I have a competitive disadvantage in stationary phase. J Bacteriol 175, 5642-5647.

Zambrano, M. M., Siegele, D. A., Almirón, M., Tormo, A. \& Kolter, R. (1993). Microbial competition: Escherichia coli mutants that take over stationary phase cultures. Science 259, 1757-1760.

Received 27 April 1999; revised 28 June 1999; accepted 23 July 1999. 